2010

\title{
Optimal Location of an Oil Storage Facility
}

Giovanni Quiel

University of South Florida

\author{
Advisors: \\ Masahiko Saito, Mathematics and Statistics \\ Scott Campbell, Chemical \& Biomedical Engineering \\ Problem Suggested By: Scott Campbell
}

Follow this and additional works at: https://digitalcommons.usf.edu/ujmm

Part of the Mathematics Commons

UJMM is an open access journal, free to authors and readers, and relies on your support:

Donate Now

\section{Recommended Citation}

Quiel, Giovanni (2010) "Optimal Location of an Oil Storage Facility," Undergraduate Journal of Mathematical Modeling: One + Two: Vol. 3: Iss. 1, Article 13.

DOI: http://dx.doi.org/10.5038/2326-3652.3.1.25

Available at: https://digitalcommons.usf.edu/ujmm/vol3/iss1/25 


\title{
Optimal Location of an Oil Storage Facility
}

\begin{abstract}
Given three oil drilling sites, we devise a method to determine the optimal location for a storage facility such that the total length of pipeline required to connect each site to the facility is minimized. First we represent the total distance of piping as the sum of the individual distances between the storage facility and each oil well. From this, both the optimal overall pipeline length and the location of the storage facility which realizes the minimal length can be determined through the first and second partial derivative tests.
\end{abstract}

\section{Keywords}

Oil Pipeline Optimization, Steiner Point, Partial Derivatives

Creative Commons License

(c) (i) (\$)

This work is licensed under a Creative Commons Attribution-Noncommercial-Share Alike 4.0 License.

\section{Erratum}

This article was previously called Article 25. 


\section{TABLE OF CONTENTS}

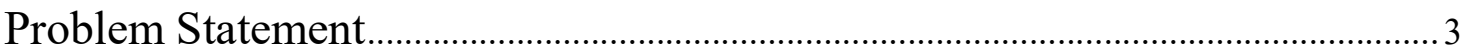

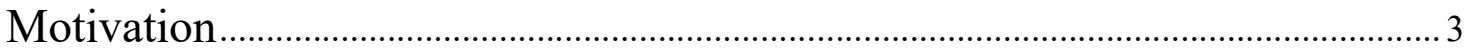

Mathematical Description and Solution Approach ….............................................. 3

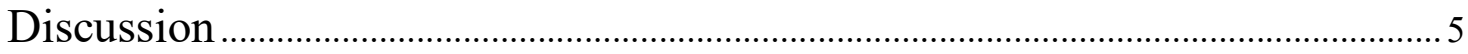

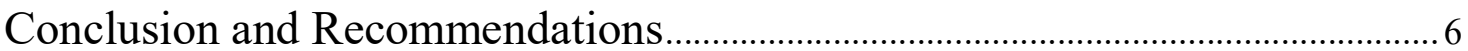

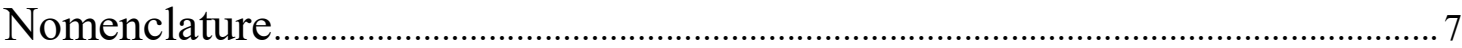

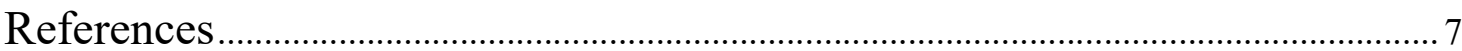

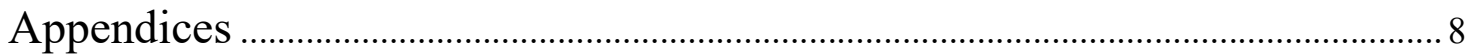




\section{PROBLEM STATEMENT}

The goal of this project is to determine the optimal location to build a storage facility that will minimize the total pipeline needed to connect the facility with three oil wells.

\section{MOTIVATION}

An engineer planning a storage facility and pipeline system around fixed drilling sites is expected to minimize the cost while maximizing efficiency. One way in which to do this is by minimizing the total pipeline length. In the real world, there may be many more factors that can affect either the cost or the feasibility of various installations. For example, different types of piping might be needed for various segments of the pipeline. Additionally, there may be obstacles that prohibit direct paths between the storage facility and an oil well. Such factors may increase the cost per unit length, the total pipeline length, and the overall cost of the installation.

\section{MATHEMATICAL DESCRIPTION AND SOLUTION APPROACH}

For three oil wells located at $\left(x_{1}, y_{1}\right),\left(x_{2}, y_{2}\right)$, and $\left(x_{3}, y_{3}\right)$, for which each supplies oil at the same rate to a storage facility, the optimal location $(x, y)$ of the storage facility is such that the total pipeline length is minimized (see Fig. 1).

The total pipeline length is equivalent to the sum of each pipeline segment between the storage facility and each oil well, given by $L_{1}, L_{2}$, and $L_{3}$. Let $L_{T}$ be the total pipeline used to connect the wells to the storage facility, i.e.,

$$
L_{T}=L_{1}+L_{2}+L_{3}
$$


The lengths of the segments may be represented as distance formulas between two points,

$$
\begin{gathered}
L_{1}=\sqrt{\left(x-x_{1}\right)^{2}+\left(y-y_{1}\right)^{2}}, \\
L_{2}=\sqrt{\left(x-x_{2}\right)^{2}+\left(y-y_{2}\right)^{2}}, \text { and } \\
L_{3}=\sqrt{\left(x-x_{3}\right)^{2}+\left(y-y_{3}\right)^{2}} .
\end{gathered}
$$

We investigate both the first and second order partial derivatives of $L_{T}$ in order to minimize the total pipeline length. The first order partial derivatives are given by

$$
\begin{gathered}
L_{x}=\frac{\left(x-x_{1}\right)}{\sqrt{\left(x-x_{1}\right)^{2}+\left(y-y_{1}\right)^{2}}}+\frac{\left(x-x_{2}\right)}{\sqrt{\left(x-x_{2}\right)^{2}+\left(y-y_{2}\right)^{2}}}+\frac{\left(x-x_{3}\right)}{\sqrt{\left(x-x_{3}\right)^{2}+\left(y-y_{3}\right)^{2}}} \text { and } \\
L_{y}=\frac{\left(y-y_{1}\right)}{\sqrt{\left(x-x_{1}\right)^{2}+\left(y-y_{1}\right)^{2}}}+\frac{\left(y-y_{2}\right)}{\sqrt{\left(x-x_{2}\right)^{2}+\left(y-y_{2}\right)^{2}}}+\frac{\left(y-y_{3}\right)}{\sqrt{\left(x-x_{3}\right)^{2}+\left(y-y_{3}\right)^{2}}} .
\end{gathered}
$$

And the second order partial derivatives are given by

$$
\begin{gathered}
L_{x x}=\frac{\left(y-y_{1}\right)^{2}}{\left[\left(x-x_{1}\right)^{2}+\left(y-y_{1}\right)^{2}\right]^{\frac{3}{2}}}+\frac{\left(y-y_{2}\right)^{2}}{\left[\left(x-x_{2}\right)^{2}+\left(y-y_{2}\right)^{2}\right]^{\frac{3}{2}}}+\frac{\left(y-y_{3}\right)^{2}}{\left[\left(x-x_{3}\right)^{2}+\left(y-y_{3}\right)^{2}\right]^{\frac{3}{2}}}, \\
L_{x y, y x}=-\left[\frac{\left(x-x_{1}\right)\left(y-y_{1}\right)}{\left[\left(x-x_{1}\right)^{2}+\left(y-y_{1}\right)^{2}\right]^{\frac{3}{2}}}+\frac{\left(x-x_{2}\right)\left(y-y_{2}\right)}{\left[\left(x-x_{2}\right)^{2}+\left(y-y_{2}\right)^{2}\right]^{\frac{3}{2}}}+\frac{\left(x-x_{3}\right)\left(y-y_{3}\right)}{\left[\left(x-x_{3}\right)^{2}+\left(y-y_{3}\right)^{2}\right]^{\frac{3}{2}}}\right], \text { and } \\
L_{y y}=\frac{\left(x-x_{1}\right)^{2}}{\left[\left(x-x_{1}\right)^{2}+\left(y-y_{1}\right)^{2}\right]^{\frac{3}{2}}}+\frac{\left(x-x_{2}\right)^{2}}{\left[\left(x-x_{2}\right)^{2}+\left(y-y_{2}\right)^{2}\right]^{\frac{3}{2}}}+\frac{\left(x-x_{3}\right)^{2}}{\left[\left(x-x_{3}\right)^{2}+\left(y-y_{3}\right)^{2}\right]^{\frac{3}{2}}} .
\end{gathered}
$$

By setting the first order partial derivatives (3) and (4) equal to zero and determining the intersection point of the two functions (see Fig. 2), a critical point for the location of the storage facility can be determined provided the critical point is a local minimum. To test this, the second order partial derivatives (5), (6), and (7) are used such that a critical point is defined as a 
minimum when $L_{x x}>0$ and $\operatorname{det}\left(H\left(L_{T}\right)\right)=L_{x x} L_{y y}-L_{x y}^{2}>0$, where $\operatorname{det}\left(H\left(L_{T}\right)\right)$ is the determinant of the Hessian matrix for $L_{T}$ (Larson, Hostetler and Edwards). Once verified as a local minimum, the critical point is taken as the coordinate for the storage facility that minimizes the total length of pipeline.

\section{DISCUSSION}

Five cases, indexed A - E, for the locations of the drilling sites were considered (see Appendix A). Additionally, plots for each of the cases appear in Appendix B. The three oil wells are represented by blue diamonds and the optimal storage facility location is represented by a red square (see Figures 3-7). The blue lines in the plots outline the perimeter of the three oil wells and the red lines show the direct paths of the pipelines from the drilling sites to the storage facility. For each case, the mathematical methodology previously described was implemented in Excel to find the optimal location for the storage facility.

For Case A, the optimal storage facility location lies with the triangle formed by the three drilling sites as seen in Figure 3. Interestingly, Cases B, C, and D had optimal storage facility locations at one of the drilling sites as seen in Figures 4, 5, and 6. Finally, Case E depicts a scenario in which the storage facility is located slightly away from the drilling site location as can be seen in Figure 7. This departure from the drilling sight led to further investigation of the criteria that result in a storage location not at a drilling sight. Using the individual pipeline segment lengths and the law of cosines, the individual angles of the triangles formed by the drilling sites were determined for each case. It was found that a triangle with all three angles less than $120^{\circ}$ will yield storage facility position interior to the oil wells, while having an angle of 
$120^{\circ}$ or greater leads to a storage facility at one of the drilling sites. This can be seen in the tables for each case within Appendix A.

Our results coincide with Heinen's 1834 solution to Fermat's question concerning minimal spanning trees (Ivanov and Tuzhilin). In this framework, the point which minimizes the distances between the oil wells is called a Steiner point. See (Ivanov and Tuzhilin) for more information on minimal spanning trees and Steiner points.

\section{CONCLUSION AND RECOMMENDATIONS}

Optimal positions for a storage facility that minimizes the total pipeline length from three drill sites were determined using the first and second partial derivatives of the total pipeline length $L_{T}$. The first partial derivative gives the critical point of interest, while the second partial derivative test determines whether this critical point value is a relative minimum, maximum, saddle point, or indeterminate. For our critical point to be a relative minimum, the value of $L_{x x}$ must be greater than zero, and the determinant of the Hessian matrix must also be greater than zero. For cases in which the triangle formed by the three drill sites had no angle greater than $120^{\circ}$, the optimal storage facility sight was located within this triangle. For cases in which the triangle had an angle of at least $120^{\circ}$, the optimal location for the storage facility was located at a drill site.

Further expansions on this project may include varying the cost of each individual pipeline segment (assume each pipe must be made differently), and optimizing cost instead of the pipeline length only. Also, as mentioned above, more realistic approaches to this problem could possibly include path obstructions, such as mountain ranges or lakes. 


\section{NOMENCLATURE}

$\begin{array}{clc}\text { Quantity } & \text { Description } & \text { Units } \\ L_{T} & \text { Total pipeline length } & \text { Miles } \\ L_{1} & \text { Length of pipeline segment 1 } & \text { Miles } \\ L_{2} & \text { Length of pipeline segment 2 } & \text { Miles } \\ L_{3} & \text { Length of pipeline segment 3 } & \text { Miles } \\ L_{x} & \text { Partial derivative of } L_{T} \text { with respect to } x & - \\ L_{y} & \text { Partial derivative of } L_{T} \text { with respect to } y & - \\ L_{x x} & \text { Partial derivative of } L_{x} \text { with respect to } x & - \\ L_{y y} & \text { Partial derivative of } L_{y} \text { with respect to } y & - \\ L_{x y} \text { or } L_{y x} & \text { Partial derivative of } L_{x} \text { with respect to } y \text { or vice versa } & \text { - } \\ \left(x_{1}, y_{1}\right) & \text { Coordinate of first drilling site } & \text { Miles } \\ \left(x_{2}, y_{2}\right) & \text { Coordinate of second drilling site } & \text { Miles } \\ \left(x_{3}, y_{3}\right) & \text { Coordinate of third drilling site } & \text { Miles } \\ \alpha & \text { Angle formed by }\left(x_{1}, y_{1}\right),\left(x_{2}, y_{2}\right), \text { and }\left(x_{3}, y_{3}\right) & \text { Degrees } \\ \beta & \text { Angle formed by }\left(x_{2}, y_{2}\right),\left(x_{1}, y_{1}\right), \text { and }\left(x_{3}, y_{3}\right) & \text { Degrees } \\ \lambda & \text { Angle formed by }\left(x_{1}, y_{1}\right),\left(x_{3}, y_{3}\right), \text { and }\left(x_{2}, y_{2}\right) & \text { Degrees }\end{array}$

\section{REFERENCES}

Ivanov, Alexander O and Alexei A Tuzhilin. Minimal Networks: The Steiner Problem and its Generalizations. CRC Press, 1994.

Larson, Ron, Robert Hostetler and Bruce Edwards. alculus. 8th Edition. Boston, MA: Houghton Mifflin Company, 2005. 


\section{APPENDIX A - TABLES}

Tables for each case of drilling site locations (From Excel)

\begin{tabular}{|c|c|c|c|c|c|c|c|}
\hline \multicolumn{2}{|c|}{ Case A (Drill Sites) } & $L_{X}=$ & $-2.7 \mathrm{E}-07$ & & \multicolumn{2}{|c|}{ Solutions (Storage Site) } & \\
\hline$x$ & $y$ & $L_{y}=$ & $1.3 \mathrm{E}-07$ & & $x$ & $y$ & \\
\hline-10 & -1 & $L_{X X}=$ & $2.73 \mathrm{E}-1$ & & 1.95 & 2.14 & \\
\hline 3 & 6 & $L_{y y}=$ & $1.28 \mathrm{E}-1$ & $L_{1}=$ & 14.76 & $\lambda=$ & $39.61^{\circ}$ \\
\hline 12 & -8 & $L_{x y}=L_{y x}=$ & $-4.84 \mathrm{E}-2$ & $L_{2}=$ & 16.64 & $\beta=$ & $45.95^{\circ}$ \\
\hline & & det $=$ & $3.26 \mathrm{E}-2$ & $L_{3}=$ & 23.09 & $\alpha=$ & $94.43^{\circ}$ \\
\hline
\end{tabular}

\begin{tabular}{|c|c|c|c|c|c|c|c|}
\hline \multicolumn{2}{|c|}{ Case B (Drill Sites) } & $L_{X}=$ & $-4.8 \mathrm{E}-07$ & & \multicolumn{2}{|c|}{ Solutions (Storage Site) } & \\
\hline$x$ & $y$ & $L_{y}=$ & $-7.38 \mathrm{E}-1$ & & $x$ & y & \\
\hline-10 & -1 & $L_{x x}=$ & $1.34 \mathrm{E}+3$ & & 3.00 & 6.00 & \\
\hline 3 & 6 & $L_{y y}=$ & $1.29 \mathrm{E}+2$ & $L_{1}=$ & 14.76 & $\lambda=$ & $9.72^{\circ}$ \\
\hline 12 & 8 & $L_{x y}=L_{y X}=$ & $1.25 \mathrm{E}+1$ & $L_{2}=$ & 9.22 & $\beta=$ & $6.05^{\circ}$ \\
\hline & & $\operatorname{det}=$ & $2.22 \mathrm{E}+2$ & $L_{3}=$ & 23.77 & $\alpha=$ & $164.22^{\circ}$ \\
\hline
\end{tabular}

\begin{tabular}{|c|c|c|c|c|c|c|c|}
\hline \multicolumn{2}{|c|}{ Case C (Drill Sites) } & $L_{X}=$ & $-4.66 \mathrm{E}-1$ & & \multicolumn{2}{|c|}{ Solutions (Storage Site) } & \\
\hline$x$ & $y$ & $L_{y}=$ & $3.3 \mathrm{E}-07$ & & $x$ & $y$ & \\
\hline 3 & 5 & $L_{x x}=$ & $1.90 \mathrm{E}+2$ & & 4.00 & 2.00 & \\
\hline 2 & -7 & $L_{y y}=$ & $-6.89 \mathrm{E}+3$ & $L_{1}=$ & 12.04 & $\lambda=$ & $149.04^{\circ}$ \\
\hline 4 & 2 & $L_{x y}=L_{y x}=$ & $2.51 \mathrm{E}+5$ & $L_{2}=$ & 3.162 & $\beta=$ & $7.77^{\circ}$ \\
\hline & & det $=$ & $9.82 \mathrm{E}+4$ & $L_{3}=$ & 9.22 & $\alpha=$ & $23.20^{\circ}$ \\
\hline
\end{tabular}

\begin{tabular}{|c|c|c|c|c|c|c|c|}
\hline \multicolumn{2}{|c|}{ Case D (Drill Sites) } & $L_{x}=$ & $5.80 \mathrm{E}-1$ & & \multicolumn{2}{|c|}{ Solutions (Storage Site) } & \\
\hline$x$ & $Y$ & $L_{y}=$ & $5.84 \mathrm{E}-07$ & & $x$ & $y$ & \\
\hline 0 & 1 & $L_{x x}=$ & $6.85 \mathrm{E}+3$ & & $8.27 \mathrm{E}-6$ & 1.00 & \\
\hline 2 & 3 & $L_{y y}=$ & $2.75 \mathrm{E}+4$ & $L_{1}=$ & 3.16 & $\lambda=$ & $14.04^{\circ}$ \\
\hline-1 & -2 & $L_{x y}=L_{y X}=$ & $1.10 \mathrm{E}+5$ & $L_{2}=$ & 2.83 & $\beta=$ & $12.53^{\circ}$ \\
\hline & & $d e t=$ & $6.73 E+4$ & $L_{3}=$ & 5.83 & $\alpha=$ & $153.44^{\circ}$ \\
\hline
\end{tabular}

\begin{tabular}{|c|c|c|c|c|c|c|c|}
\hline \multicolumn{2}{|c|}{ Case E (Drill Sites) } & $L_{X}=$ & $-9.50 \mathrm{E}-8$ & & \multicolumn{2}{|c|}{ Solutions (Storage Site) } & \\
\hline$x$ & $y$ & $L_{y}=$ & $5.67 \mathrm{E}-7$ & & $x$ & $y$ & \\
\hline 3 & 5 & $L_{X X}=$ & $6.65 \mathrm{E}-1$ & & 5.44 & 1.99 & \\
\hline 2 & -7 & $L_{y y}=$ & -2.53 & $L_{1}=$ & 12.04 & $\lambda=$ & $118.94^{\circ}$ \\
\hline 5.5 & 2 & $L_{x y}=L_{y X}=$ & $1.66 \mathrm{E}+1$ & $L_{2}=$ & 3.91 & $\beta=$ & $16.49^{\circ}$ \\
\hline & & $\operatorname{det}=$ & 4.61 & $L_{3}=$ & 9.66 & $\alpha=$ & $44.57^{\circ}$ \\
\hline
\end{tabular}




\section{APPENDIX B - PlOTS}

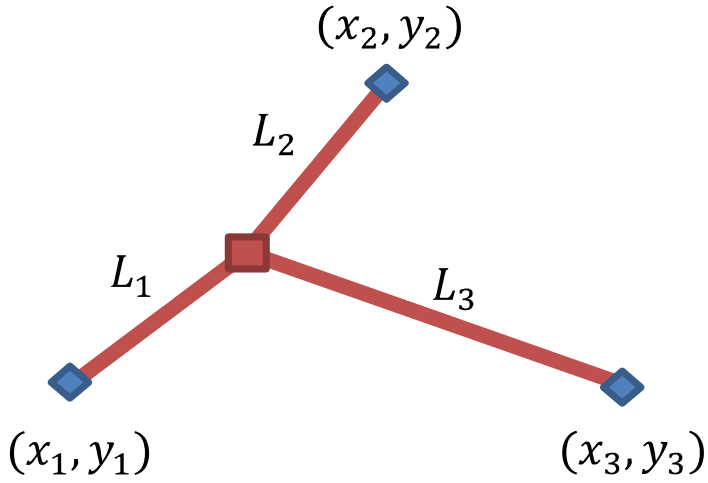

Figure 1: General schematic for drilling sites (diamonds) and storage facility (rectangle).

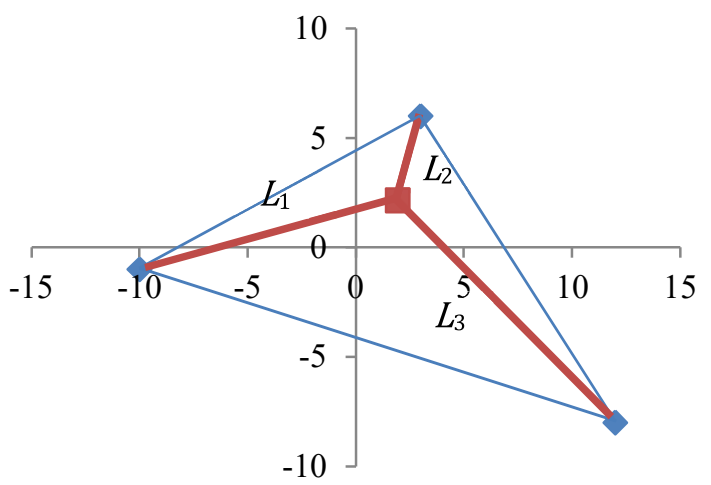

Figure 3 (Case A): Oil wells are depicted by diamonds, while the storage facility by a square. The blue lines show the perimeter around the oil wells, and the red line shows the shortest distance to the storage.

Optimal Location: $(1.95,2.14)$

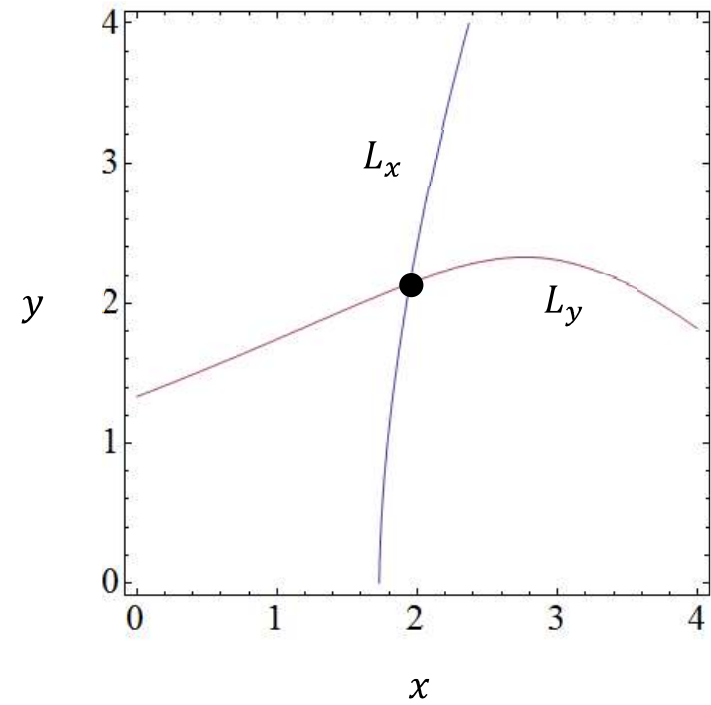

Figure 2: Plot of $L_{x}$ vs. $L_{y}$ for Case A. The intersection of $L_{x}$ and $L_{y}$ is at $(\mathbf{1 . 9 5}, \mathbf{2 . 1 4})$.

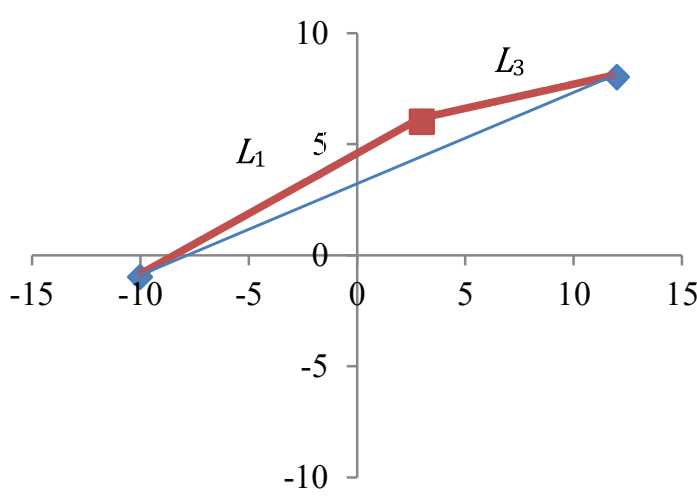

$L$
Figure 4 (Case B): Oil wells are depicted by blue diamonds, while storage facility by a red square. The position that minimizes total pipeline length is at one of the drilling sites.

Optimal Location: $(3.00,6.00)$ 


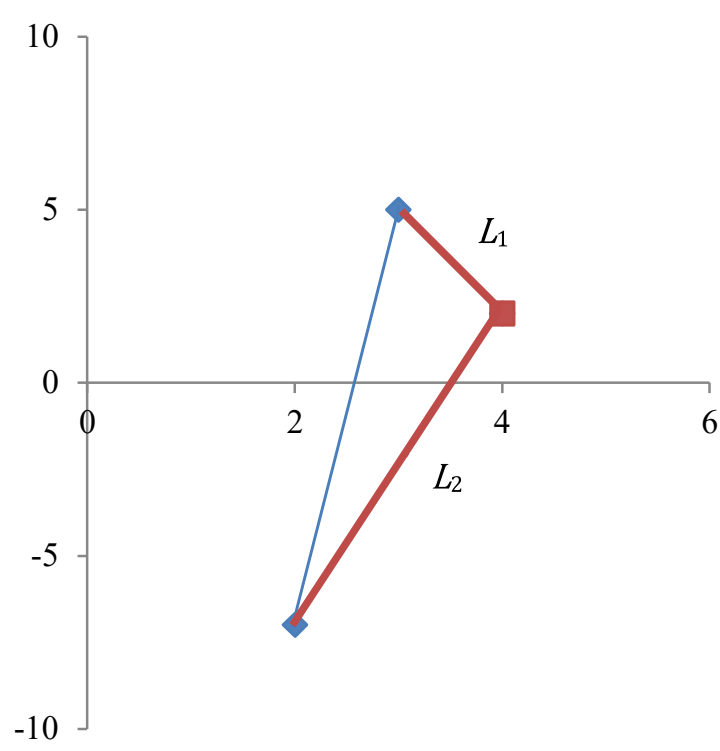

Figure 5 (Case C): Oil wells are depicted by blue diamonds, while storage facility by a red square. Again, the storage facility must be placed at a drilling site to minimize pipeline length.

Optimal Location: $(4.00,2.00)$

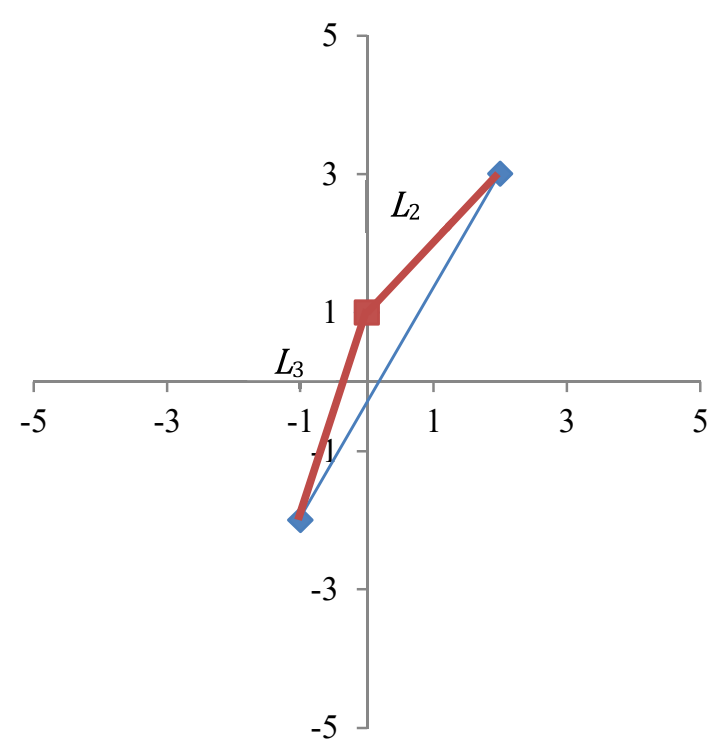

Figure 6 (Case D): Oil wells are depicted by blue diamonds, while storage facility by a red square. As in Cases B and C, the storage facility must be placed at an oil well to minimize total pipeline length.

Optimal Location: $(0.00,1.00)$

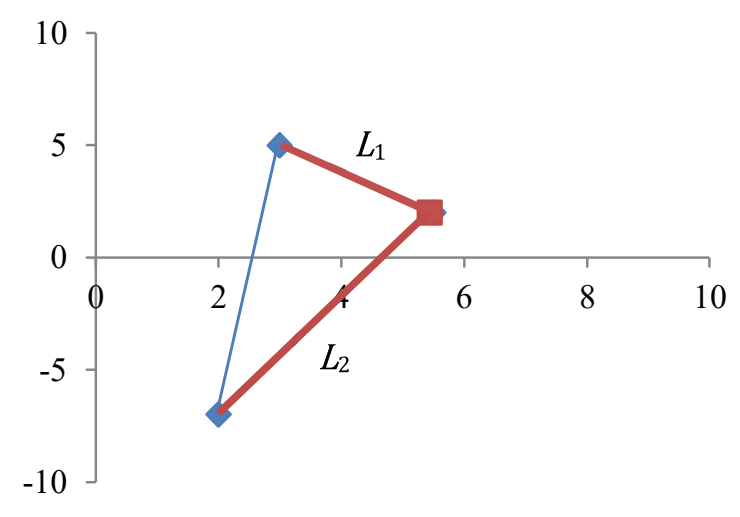

Figure 7 (Case E): Oil wells are depicted by blue diamonds, while storage facility by a red square. The storage facility is located just inside the triangle formed by the drilling sites as the vertex of $L_{1}$ and $L_{2}$.

Optimal Location: $(5.44,1.99)$ 